\title{
The system of Informational Support for University Management
}

\author{
Valeriy Poluboyarov," \\ Volgograd State University, IT Department, 400062 Volgograd, Universitetsky Ave., 100, Russia
}

\begin{abstract}
The article defines the place of information technologies in the system of strategic managing of the higher educational institution (HEI). The author analyzes the Russian regulatory requirements for the system of informational support for university management and proposed the architecture model of the typical informational system of university management. The market of software for automation of business processes within the university was also analyzed: platforms for building the systems of university management, platforms for building electronic informationeducational systems, platforms for management informational support according to objectives. The article describes the architecture of the system of informational support for university management that has been embedded in Volgograd State University and the mechanisms of its integration, additional functionality implemented there, and development plans.
\end{abstract}

\section{Introduction}

In accordance with a new vision of the university role as a centre for innovative, advanced technological and social development of the region [1] by the university founder in the person of the Ministry of education, it becomes even more urgent to improve the efficiency of managing the educational institution. One of the modern methods to manage a university is a strategic approach that assumes the development of a comprehensive and long-term plan of systemic actions and their actual implementation through a comprehensive study of all laws, external and internal circumstances, goals and objectives, ensuring the effectiveness of the organization activity [2], [3].

\section{Requirements for the system of informational support for university management}

\subsection{The system of informational support for managing a university as a strategic management tool}

The development of such a strategy allows determining the specificity of the university in the context of cooperation with the region, identifying the points of growth and development opportunities, organizing and coordinating activities, plans and projects.

The approaches to the development of the strategic management system in Russian universities can be divided into three main groups: based on management by objectives (MBO), the balanced scorecard (BSC), and consideration of the HEI as an integrated two-tier system. This differentiation is rather conditional and reflects some of the essential differences in the approaches to developing the strategy of the educational institution that preserves the unity in the logic of the process and applicable tools.

The system of management by objectives (MBO) is a management approach that can be defined as the process of identifying objectives and criteria of the efficiency of employees, individual units (or entire organization) and coordinating efforts (resources) to achieve them [4]. Modernizing this system assumes the balanced scorecard (BSC) [5] including inseparable dimensions of both financial and non-financial nature (Customer, Internal processes, Growth and development). Each dimension has its own set of Key Performance Indicators (KPIs). A special feature of the BSC approach is the integration of the methods of systemic and process approaches to management and maintaining liaison between the motivation of the staff and the efficiency of the work within the organization as a whole [6].

The need for informational support of developing and implementing the university development strategy sets out the requirements to the structure and objectives of the informational support system for managing the higher educational institution. The tasks of such systems are to maintain interaction with the external environment, to effectively apply the available resources, to provide informational support of implementing major (education, science) ensuring business processes, management and development processes [7-9].

\footnotetext{
* Corresponding author: vvp@ volsu.ru
} 


\subsection{Regulatory requirements for the system of informational support for university management}

The functions of the informational support system for university management are also determined by a number of regulations. The Federal state educational standards of the generation $3++$ include the requirements for the Electronic information-educational environment (EIEE) of the university and electronic library system (ELS). The Russian Government Decree No. 582 of 10 July 2013, the order of the Federal Education and Science Supervision Service No. 785 of 29 May 2014, as well as the information letter of the Federal Education and Science Supervision Service No. 07-675 of 25 March 2015 endorse the requirements for the website of the educational organization. The order of Ministry of Education and Science dated No. 715 of 31 July 2018 regulates the operation of the system of managing the admission campaign, including requirements for the system of communication with applicants through the website of the university, as well as integration between the Federal information system of State Final Examination and the university admission system (FIS of SFE and UAS). In the framework of the activities to affect the transition to digital government, the order of the Ministry of Education and Science No. 874 of 6 September 2017 endorses the need to integrate all university systems with the state system 'Contingent' designed to record information on training and education, including information relating the education of individuals with disabilities, special needs and disadvantages. In addition, Russian Government Decree No. 729 of 26 August 2013 offers to finish the process of forming the Federal Register of the obtained academic and qualifications certificates, documents on education (FRDE) by 2023. The order of Ministry of education and science No. 717 of 16 June 2016 regulates the need for developing the plan of financial and economic activities (FEA) of the University through the use of the Federal service of Computer-Assisted Management (CAM PFEA).

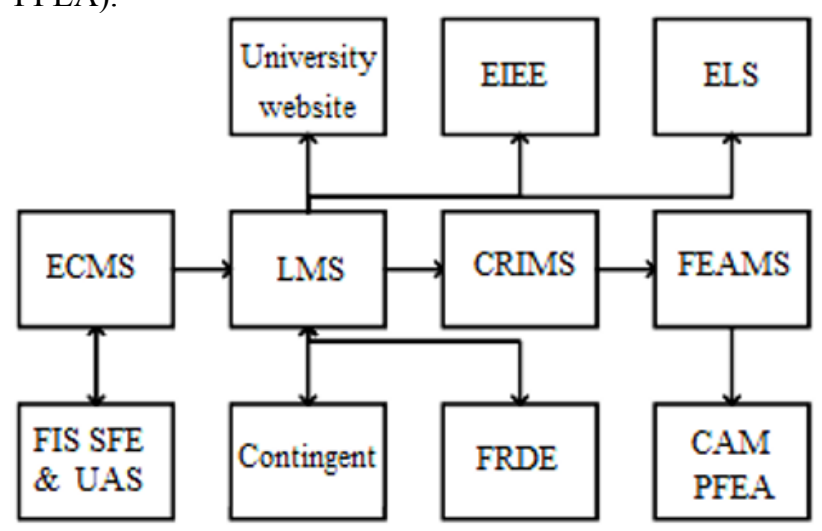

Fig. 1. The architecture model of the university management informational system.

\section{The analysis of the market of software for automation of business processes within the university}

\subsection{Analysis of the platforms for building university management systems}

It should be noted that there are no current products covering the whole range of needs of the university in effective information systems. Therefore, the universities have to solve the task of choosing individual components of a complex system, and their improvement and integration. The Russian market offers a wide range of platforms for building university management systems: 'Tandem University', 'Galaxy:University management', 'Naumen University', Learning Management System 'Magellan', '1C:University' and several others. From a functional point of view, these products are roughly equivalent: basic functions for managing the admission campaign and educational process are implemented in all products. The main criteria for choosing a platform for the university, determining the total product's running cost and the successful implementation of the entire system, include a technological platform itself where a software product is built, the availability of local expertise on the platform and the product, and potential integration opportunities. Among these products, the system '1C:University' uses the most common platform for developing application software in Russia '1C:Enterprise 8', which leads to the presence of organizations that are franchisee of the company, that develops the platform, in all cities of Russia, including major cities, and thus leads to the presence of experts in the system '1C:University'. This allows the universities during the implementation to use not only their own experts, but also to rely on external contractors. Extensive integration opportunities of the system '1C:University' are due to the fact that it uses the same software platform as the most common university accounting and personnel systems - '1C:Accounting for government institutions' (1C:AGI), '1C:Salary and personnel of government institutions' (1C:SPGI), and the system of managing financial and economic activities (FEAMS) 'Omega. FPM' (financial planning and management) [10]. These factors drive the use of '1C:University' because of a significant number of Russian universities (the developer's site has current information about 57 implementations), including Volgograd State University.

\subsection{Analysis of the platforms for building electronic information-educational systems}

The markets selling platforms for creating university EIESs also presents a significant number of products. They include global products 'Moodle' and 'BlackBoard', and local ones 'Prometheus', 'eLearning Server', 'iSpring Online', '1C:E-learning. Educational organization' and several others. The selection criteria include the availability of localization, compatibility with the SCORM format of the educational content, the ability to 
use third-party modules, including integration with ELS and webinar terminals, the availability of a public API. The disadvantages of all these products, with the exception of '1C:E-learning', cover the absence of the functional integration with the learning management systems. However, the current functionality level of this product does not allow considering it as a full EIES. Based on these criteria, a significant number of Russian universities selects 'Moodle' as a platform for creating EIES. Volgograd State University also made this choice to use the system 'Russian Moodle 3KL' by the company "Open technologies", which is a localization of the base system with extra functionality that implements, in particular, integration with a webinar service eTutorium.

\subsection{Analysis of the platforms for informational support of management by objectives}

There are many foreign and domestic platforms which can be used by universities to provide informational support of management by objectives. Modern foreign products include 'Andara Business Intelligence', 'BSC Designer Online', 'Corporater', 'Clearpoint Strategy' and several others. Most of them provide the user with the interface built on the dashboard principle. The most functional of these products has the functionality of data analysis, including big data (e.g., 'Andara BI' uses Hadoop), budgeting, planning, and enterprise management ('Corporater'). Despite the great potential for integration with the data source systems, such systems often miss any adequate adaptation to the specific informational support of management by objectives in Russian HEIs, and the localization of the user interface. Most of them are provided as a service that carries significant risks in terms of escalating sanctions.

As an example of domestic products, intended for implementing management by objectives, we can specify the KPI MONITOR Analyzer, 1C:Management by objectives and KPI. The latest product created on the platform '1C:Enterprise' has wide architecture potential to integrate with other systems on this platform, widely used in universities, e.g., '1C:University', '1C:Accounting of the governmental institution', '1C:Salary and personnel'. The model "Strategic University Management" for the system of business modelling Business Studio contains basic perspectives to build a balanced scorecard. For each perspective, we have formulated main strategic goals of the university. There are also defined the indicators and target values. However, the integration potential of the system Business Studio can be assessed as modest. We should especially note the application "Personal account of the rector" by the company Proscom, which uses a scorecard of the Ministry of Education and Science and the data from the internal systems of the Ministry. The system 'Rector.Assistant' is also worth mentioning; it is being developed by the project office Mari State University, implemented as an add-on to the bus of integration and interaction with the systems '1C:Accounting of governmental institutions', 'ARBIS: Salary and personnel management', '1C:State and municipal procurement'. The disadvantage of the system is the lack of real-time integration with systems for learning management and accounting for research and innovation activities. In General, we can conclude that there is no ready-made solution that could be recommended to all universities. Considering the specificity of the internal accounting systems of the university, the implementation of the integration project is required.

\section{The system of informational support for university management at Volgograd State University}

\subsection{System architecture}

The system architecture of informational support for university management, realized at Volgograd State University, is given in fig. 2:

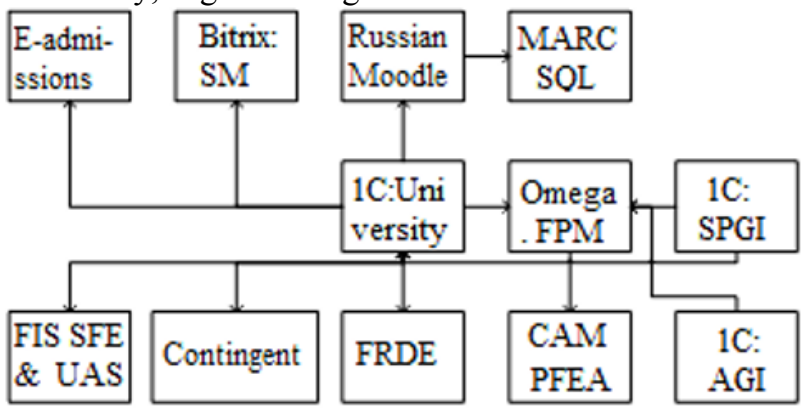

Fig. 2. The system architecture of informational support for managing Volgograd State University.

The main component of the system is the product that automates the main business processes of the university, its educational and scientific activities. This product here is '1C:University' which manages the admissions campaign, planning and implementing the educational process, accounting for the contingent movements on the basis of orders. The regular functionality of the product allows sharing the information with Federal information systems (FIS of SFE and UAS, Contingent, FRDE).

One of the modern solutions of the problem of increasing internal efficiency of the university is the use of modern approaches to financial management. A personnel and finance unit of functionality in VolSU is implemented through '1C:Accounting of governmental institutions', '1C:Salary and personnel of governmental institutions', as well as product 'Omega.FPM' which is used for financial and economic planning within the university and exporting plans and reports to the Federal system CAM PFEA. The fact that all of these products are developed on the platform '1C:Enterprise' significantly simplifies the administration and maintenance of the infrastructure.

One of the key components of the system of informational support for university activities is EIES allowing all participants of the educational process to access information resources of the university. The functionality of EIES is implemented in VolSU through the system 'Russian Moodle 3KL'. The system enables 
students to access the curriculum, syllabuses of disciplines (modules) and practices, electronic textbooks and electronic educational (e-learning) resources (by providing user access to electronic library system book.ru and IPRBooks), specified in the syllabuses of disciplines (modules) and practices. There is also a mechanism for making an electronic portfolio of the student, including the preservation of his works and grades for this work. Another feature of the system is capturing the educational progress, the results of the interim assessment and the final results of acquiring the curriculum. To implement the specified functionality in accordance with the curriculum there are some categories and courses set up, which publish student aids or learning and teaching support kits in current curricula.

The university website is developed using content management system '1C-Bitrix: site Management'.

\subsection{Mechanisms of integration}

To enable the functioning of individual products as a single system, we used the regular mechanisms of integration of these systems, as well as developed the new ones. The primary record of the teaching staff is kept in the system '1C:Salary and personnel of governmental institutions'. The system '1C:University' has an established mechanism to import information about the teaching staff from this system, which allows synchronizing this information twice a year. The same information achieves the system 'Omega.FPM' with the same help of standard mechanism.

For the full implementation of the EIES's functionality, there was the developed integration functionality between the systems '1C:University' and 'Russian Moodle 3KL'. Using the established and new developed web services of the platform 'Moodle', we managed to implement the mechanism allowing to create within EIES the categories, corresponding to the curricula made inside the system '1C:University', and courses that can meet the given curriculum. We also developed a mechanism to automate publication in EIES of the scanned copies of approved curricula, syllabuses of courses and sets of assessment tools, physically stored inside the system '1C:University'. To authorize the users of the EIES we use Active Directory service. For the batch creation of student's user accounts in Active Directory, there has been a developed mechanism to export lists of students from '1C:University' using the Powershell script. In addition, with the use of Moodle web-services, we implemented the functions for automated subscribing the student's account for the courses within the curriculum where this student studies.

To comply with legal requirements to publish the information on current curricula and teaching staff on the university website, we have developed the components for content management system '1C-Bitrix:Site management' that can import the specified data from the system '1C:University' and display them on the given website using web-services.

\subsection{Developing extra functionality}

In order to inform applicants about the admission campaign progress through the technology Yii2, we developed a web-application 'University E-admissions'. The application allows the applicant to apply for admission to one or more educational programmes, to control their position in the ranking of applicants in terms of each educational program online. The data source is a subsystem 'Enrollment campaign' of '1C:University' (ECMS).

Within the system ' $1 \mathrm{C}$ :University' we have developed a system to manage the contract-related information (CRIMS). The functions were implemented to conclude contracts for educational services, to assess payments, to manage payments and reports. In addition, the functions appeared to manage contracts, concluded with staff and students, for performing research works. Recorded information about the contracts provides primary data for the system of planning financial and economic activities.

We have developed a certain functionality within the system '1C:University' to register different types of publications by the faculty staff, professional development activities attended by teachers. This allowed a more complete accounting of the information about the faculty staff, performing managerial decisionmaking and publishing information on the website. There was also a developed reporting system for these indicators.

In the context of implementing managerial functionality, a subsystem 'Plans and reports of the university departments' has also been developed in the system '1C:University', allowing the university departments to plan for the coming year and report on the performed work for the past year. A large part of the report parameters is filled automatically on the basis of accounted university activity indicators. Implementation of the entire functionality on primary accounting of the indicators on the basis of ' $1 \mathrm{C}$ : Enterprise 8 ' helped us to solve integration tasks and to provide an adequate calculation of the indicators.

Building a fully functional support system for strategic management requires further refinement of the system by expanding the set of indicators and creating the planning functionality for institutions and the entire university [11].

\section{Conclusion}

Thus, the executed analysis of the market of software for business processes automation within the university showed a lack of integrated solutions and the need to address integration challenges to build a system from individual components. The article describes the architecture of the system of informational support for university management that has been embedded in Volgograd State University and the mechanisms of its integration, additional functionality implemented there, and development plans.

The study is carried out with the financial support of the Russian Foundation for Basic Research and the Administration of the Volgograd Region, in the framework of the project 
"Financial and Mathematical Models and Budgeting Algorithms for the Structural Divisions of Educational Organizations" No. 17-12-34015.

\section{References}

1. Passport of the priority project "Universities as centres for creating the innovation space". Approved by the Presidium of the Presidential Council of the Russian Federation for strategic development and priority projects (report No. 9 of October 25, 2016)

2. Sigrun Nickel. Handbook for Decision-makers and Administrators 1, D 2-1 (2011)

3. E. Malushko, O. Maletina, V. Lizunkov, V. Tsybaneva, International Multidisciplinary Scientific Conferences on Social Sciences and Arts, 481-487 (2016)

4. P. Drucker, The Practice of Management (Harper, New York, 1954; Heinemann, London, 1955; revised edn, Butterworth-Heinemann, 2007)

5. Robert S. Kaplan, D. P. Norton, The Balanced Scorecard - Measures That Drive Performance, Harvard Business Review (January-February): 7179 (1992)

6. M. Hladchenko, International Journal of Educational Management 29, (2015), URL: http://www.emeraldinsight.com/doi/abs/10.1108/IJE M-11-2013-0164 (date of access: 20.05.2018)

7. P.R. Niven, Balanced Scorecard: Step-by-Step for Government and Nonprofit Agencies: Second Edition (2015)

8. Mazen Shobaki, Samy Abu NaserInternational Journal of Advanced Research and Development 1 (10), 33-47 (2016)

9. Elva Ramos, Xavier Llinás-Audet, Jesus BarrenaMartinez, Universities as Corporate Entities: The Role of Social Responsibility in Their Strategic Management. Corporate Governance and Strategic Decision Making (2017)

10. N.V. Filipenko, V.V. Poluboyarov, University management: practice and analysis 21, 6 (112), 5867 (2017)

11. N.V. Poluboyarov, Izvestia VSTU 20, 17 (144), 7684 (2014) 